\title{
Psychological factors affecting flood coping strategies
}

\author{
C. B. Rose ${ }^{1}$, D. G. Proverbs ${ }^{1}$, K. Manktelow ${ }^{2} \&$ C. A. Booth ${ }^{1}$ \\ ${ }^{I}$ School of Engineering and the Built Environment, \\ University of Wolverhampton, UK \\ ${ }^{2}$ School of Applied Sciences, University of Wolverhampton, UK
}

\begin{abstract}
There is an acknowledged need to improve the resilience of those at risk of flooding in areas of the UK. Studies of disaster preparedness worldwide indicate raising awareness of a hazard does not necessarily engender action. In the UK the majority of the at-risk population do not display adaptation behaviours until they have experienced one or more flood events, a finding not adequately explained by levels of information provision or financial pressures. An appreciation of the psychological underpinning of current behaviour patterns, including decision-making processes, can illuminate our understanding of the strategies employed. A review of relevant psychological theories affecting adaptation behaviours in a variety of hazard situations is presented. It is suggested that psychometric measures might be employed as capability indicators and the adoption of such techniques may contribute to an improved resilience in the future.
\end{abstract}

Keywords: flood, resilience, psychology, preparedness, adaptation, capability.

\section{Introduction}

In the context of anticipated climate change [1], the UK government has enacted legislation in the form of the Climate Change Act [2]: increasingly worldwide attention is focussed upon assessing vulnerability to extreme events, improving upon recovery plans to deal with their aftermath and examining the ways in which adaptation to climate change might enhance resilience in the future. 


\section{Awareness raising}

Campaigns intended to promote protective behaviours via awareness-raising may not always be as successful as the policy-making bodies might have hoped: an annual campaign on flood-risk within England and Wales has been in place since 2001 , but it has been found that only $60 \%$ of at-risk residents claimed to be aware they lived in a flood risk area [3]. Similarly, a free telephone flood warning system for at-risk properties has been available throughout this period, but at the time of the summer 2007 flood events, only $41 \%$ of eligible homes were registered for the Floodline Warnings Direct service [4]. Such behaviour patterns are not unique to the UK, nor are they peculiar to flood risk, as some samples of the literature on natural hazards worldwide will reveal [5-8]. The consistency of these findings (that awareness does not engender action) suggests that, in order to change human behaviour patterns, a more sophisticated approach may be required, as discussed by Fischhoff [9]. An examination of the psychological theories covering decision-making and behaviour change, which may play a part in flood coping strategies, may offer a way forward in promoting resilient adaptation.

\section{Psychological theories of decision-making}

In the second half of the $20^{\text {th }}$ century, psychologists initially viewed decisionmaking as being a predominantly rational process, involving logic, reason and consideration of all possible risks and benefits associated with a particular decision [10]. This 'rational actor paradigm' would, however, be an extremely time-consuming strategy, if employed afresh for each decision that human beings must undertake. It was, therefore, suggested that instead human beings commonly employ mental short-cuts, based upon experience, such as 'heuristics' to arrive at solutions swiftly [11]. Thus, when asked to estimate the probability of an event occurring, a person might employ the 'availability heuristic': they will make use of the associations most available, in that they can be brought to mind readily. Aircraft crashes, though in fact comparatively rare occurrences are easily brought to mind because they receive so much media exposure and are, therefore, thought to be more common than they really are. An alternative view [12] suggests human beings make use of 'fast and frugal' algorithms to make probabilistic judgements; for instance, memory is searched for cues to the problem and the first cue that is diagnostic will be adopted as the solution. As with heuristics, such a mechanism would provide a more time-efficient method of arriving at a conclusion, consistent with the cognitive limitations of human decision-makers.

\section{Decision-making in risk environments}

Although the above models can offer coherent explanations for many individual decision processes, and indeed some social choice situations, more complex 
mechanisms seem to pertain to human behaviour under conditions of uncertainty such as disaster preparedness. The 'psychometric paradigm', incorporating the heuristics argument, is a theoretical framework developed by Slovic et al. [13]. This assumes risk is fundamentally subjective, and defined by individuals in accord with the influence of psychological, social, institutional and cultural factors. In respect of natural hazards, the 'affect heuristic' was identified as an important factor: this short-cut makes use of the feelings associated with a given stimulus, for example liking the subject (positive affect) or disliking it (negative affect) [14]; this might colloquially be termed the 'gut reaction' to a situation. The relationships between perceived risk, perceived benefit and risk acceptance are complex, but another consistent finding has been that where perceived benefits are deemed to be high, the associated risks will be perceived as low and vice versa. This inverse correlation principle is harnessed by, notably, the advertising industry: product campaigns tend to emphasise the benefits of the goods or services offered, perhaps employing emotional content in order to do so; a health promotion campaign, however, is more likely to highlight the risks of a given behaviour, with the intention of deterrence or discouragement. A causal relationship here has been demonstrated [15], but careful consideration of behavioural theory is required, in order to identify the critical beliefs underlying the intentions of the target population if campaign materials are to be effective [16]. Another psychological theory of relevance here is prospect theory [17] which considers the importance of the 'framing' of problems, such as whether the result of a gamble will be a gain, or a loss, relative to the reference point of the current state. Expressing outcomes in terms of financial costs and benefits clearly resonates with the behaviour of residents in flood-risk areas, when they are considering investment in mitigation measures. Such decisions may also have timing implications: a dilemma can be seen to exist between short-term expenditure and long-term potential savings, and different groups of people will make different choices in the same situation. This issue may also be viewed in the context of motivational priorities [18]: it is in accordance with a rationality model that immediate and pressing needs would be addressed in preference to longer-term needs, especially if the latter are uncertain.

\section{Social factors in decision-making}

As social animals, our decision-making processes are influenced by the societies in which we live: there is the option to act as an individual, or to conform to a group norm. For example, a householder may wish to buy and install flood resilient products, in order to protect their own property; however, a dilemma can arise if $\mathrm{s} / \mathrm{he}$ is aware this approach could attract opprobrium from neighbours who believe advertising the existence of a flooding problem will affect the saleability of their own homes [19]. The ability to withstand social pressures, such as this, will vary between individuals, and indeed groups of people; hence, bringing personality factors into the, already complex, problem. Other sociocultural values, beliefs or superstitions exert effects on different sectors of the atrisk population [20-22]. The scope for misunderstandings in relation to flood 
risk has been well documented: for example, it was found that a widespread assumption was that dams actually built for hydro-electricity generation were flood-control structures [23]. A cultural misapprehension was noted by in relation to the Easter 1998 flood event in Banbury, wherein some recent immigrants to the UK expressed surprise in that they had not expected to be flooded in a developed country [24]. Such belief systems, therefore, pose an additional contributory factor in decisions relating to flood risk adaptation. It has been noted that floodplain populations tend to ignore flood risk until either regulation, or repeated flood events, brings about behavioural changes [25]. A motivational mechanism for this phenomenon has been suggested: people without flood experience envisaged the consequences of a flood differently from people who had actually experienced severe flood losses [26]. In psychological terms, therefore, they underestimated the 'negative affect' associated with a flood: this has obvious implications for communication of warning campaigns across natural hazard scenarios, in that the potential for negative emotional consequences should be incorporated into educational materials, as well as information on mitigating tangible losses.

\section{Measuring beliefs}

Belief systems can have strong influences on decision-making processes, not only in hazard adaptation contexts, but also in fields such as health, education and occupational psychology. Such beliefs may pose a barrier to action, even where awareness of hazard and knowledge of possible mitigation strategies both exist. Constructs offering explanations for belief-driven behaviours have been developed, as have techniques to measure these constructs; those used most widely in natural hazard studies will now be outlined.

\subsection{Locus of control}

This construct is derived from Rotter's Social Learning Theory [27]: where experience leads an individual to believe $\mathrm{s} / \mathrm{he}$ is responsible for the outcomes of their actions, that person tends to develop an 'internal locus of control'. If forces external to the individual are perceived to be responsible for outcomes, however, the learning process is likely to result in the development of an 'external locus of control'. The Internal/External score (hereafter $\mathrm{I} / \mathrm{E}$ ) is typically measured via a forced choice expression of belief in a list of statements, such as:

a. Many of the unhappy things in people's lives are partly due to bad luck. b. People's misfortunes result from the mistakes they make.

In an educational context, it has been found having an internal locus of control contributed to the educational attainment of US teenagers, operating via their expectations of the return on 'investment' represented by completing high school [28]. In studies of natural hazard behaviours, statistically significant correlations between behaviours and I/E scores were found in the context of earthquake preparedness [29]. It should be noted the locus of control orientation 
provides a measure of cross-situational beliefs, or generalised control beliefs, contrasting with the next concept to be examined

\subsection{Self-efficacy}

This concept refers to an individual's convictions (or confidence) about his or her abilities to mobilize the motivation, cognitive resources, and courses of action needed to successfully execute a specific task, as opposed to the more generalized locus of control scale discussed above. Self-efficacy, measured by means of a psychometric scale, has been utilised in human performance studies: employees who perceive themselves as highly efficacious will display a strong sense of commitment to their activities and, if these are well executed, produce successful outcomes; those who perceive their self-efficacy to be weaker will tend to lose confidence in their personal abilities and fail at set tasks [30].

\subsection{Strength of belief}

A key characteristic of climate change adaptation is the inherent uncertainty around the causes and, indeed for some individuals and groups, doubt as to the existence of the problem itself. This is in direct contrast to models deriving from studies in the health sphere, where issues such as disease diagnosis are selfevidently real. The roles of strength of belief in climate change itself, and strength of belief in personal adaptive capacity, have been examined in the context of adaptations to forestry management in Sweden [31]. A significant positive association between the first characteristic and adaptation actions was identified, as was a significant association between lack of such belief and motivation for not adapting. They conclude the pre-requisites for positive adaptation were strong beliefs in the hazard itself, and the belief that, as an individual, a person has the power to do something about the hazard.

\section{Psychometric measures as a predictor of capability}

In respect of disaster warning responses, consistent correlations have been noted between internal locus of control scores and behaviour; warnings need to be heard, believed, personalised and acted upon in order to be effective, and these behaviours are more likely to be found in internal, rather than externally, oriented people [32]. An investigation of disaster preparedness relating to hurricanes in the US, found age, prior experience of a hurricane and locus of control score were amongst the predictors of preparation behaviours [33]. The self-efficacy construct has also been found to be of value in a disaster resilience contexts: for example, it has been found that has low self-efficacy scores equated to a feeling of being 'not competent to act' and, thus, the risks (in this case volcanic hazard effects) were perceived as insurmountable [5]. Although suitable techniques for measures individual constructs exist, the conceptual models currently in existence are largely, though not entirely, derived from the field of health studies and, thus, lack the 'strength of belief' element that impacts upon behaviours relating to climate change adaptations. Formulation of a suitable 
hazard-preparedness model, together with psychometric instruments capable of measuring key variables could, therefore, be of value in taking forward the prediction of behaviours thereby aiding the targeting of interventions optimal to the at-risk groups under consideration.

\section{Summary}

This review has examined the psychological factors found to be of relevance in disaster preparedness, including the flood risk context. Drawing upon both decision-making theory and belief system constructs, the theories underpinning some current behavioural models have been described. The particular constraints operating in climate change related studies are found not to be reflected in those models derived from the health study field and, thus, further work in relation to flood preparedness behaviours in the UK is required.

\section{References}

[1] UK Climate Impacts Programme, <http://www.ukcip.org.uk/>.

[2] Climate Change Act 2008. HMSO: London. 2008.

[3] Harries, T., Householder responses to flood risk; the consequences of the search for ontological security $\mathrm{PhD}$ thesis Middlesex University: London. p. 255, 2007.

[4] Pitt, M., The Pitt review, interim report.: H M Govt Cabinet Office, London, 2007.

[5] Paton, D., Smith, L.M. \& Johnston, D., Volcanic hazards: risk perception and preparedness. New Zealand Journal of Psychology. 29(2): pp. 86-91, 2000

[6] Knocke, E.T. and K.N. Kolivras, Flash Flood Awareness in Southwest Virginia. Risk Analysis, 2007. 27(1): p. 155-169.

[7] McGee, T.K. and Russell, S., "It's just a natural way of life..." an investigation of wildfire preparedness in rural Australia. Environmental Hazards, 5(2003), p. 1-12, 2003.

[8] McClure, P.J., Guidelines for encouraging householders' preparation for earthquakes in New Zealand - report for Building Research, Victoria University of Wellington: Wellington, New Zealand, 2006.

[9] Fischhoff, B., Risk Perception and Communication Unplugged: Twenty Years of Process. Risk Analysis, 15(2), pp. 137-145, 1995.

[10] Jaeger, C.C., et al., Risk, Uncertainty and Rational Action, Earthscan Publications: London. 2001.

[11] Tversky, A. and Kahneman, D. Availability: A heuristic for judging frequency and probability. Cognitive Psychology, 5, pp. 207-232, 1973.

[12] Gigerenzer, G. and Goldstein, D., Reasoning the fast and frugal way: Models of bounded rationality. Psychological Review, 103, pp. 650-669, 1996.

[13] Slovic, P., B. Fischhoff, and S. Lichtenstein, Perceived risk: psychological factors and social implications. Proceedings of the Royal Society of 
London: Series A, Mathematical and Physical Sciences, 376, pp. 17-34, 1981.

[14] Zajonc, R.B., Feeling and thinking: Preferences need no inferences. American Psychologist, 35(2), pp. 151-175, 1980.

[15] Finucane, M., et al., The affect heuristic in judgements of risks and benefits. Journal of Behavioral Decision-Making, 13, pp. 1-17, 2000.

[16] Fishbein, M. and Cappella, J., The role of theory in developing effective health communications. Journal of communication, 56, pp. S1-S17, 2006.

[17] Kahneman, D. and Tversky, A., Prospect theory: An analysis of decision under risk. Econometrica, 47, pp. 263-291, 1979.

[18] Harries, T., Feeling secure or being secure? Why it can seem better not to protect yourself against a natural hazard. Health, Risk \& Society, 10(5), pp. 479-490, 2008.

[19] Garland, P., Flooding - A Personal Perspective. Flood Repair Network Workshop no 4, 08/05/08 Embassy House, Birmingham UK. 2008.

[20] Smith, B., Coping as a predictor of outcomes following the 1993 Midwest flood. Journal of Social Behavior and Personality, 11(2), pp. 225-239, 1996.

[21] Bhatti, A., Risk Perception, Culture and Communication: A South Asian Experience. in 5th conference of the European Sociological Association, disaster and social crisis research network sessions (August 28-September 1, 2001, Helsinki, 2001.

[22] Plapp, T. and Werner, U., Understanding risk perception from natural hazards: examples from Germany. RISK 21 - Coping with Risks due to Natural Hazards in the 21st Century, ed D.V. Amman, Taylor \& Francis Group: London, pp. 101-108, 2006.

[23] Lave, T.R. and Lave, L.B., Public perception of the Risks of Floods: Implications for Communication. Risk Analysis, 11(2), pp. 255-267, 1991.

[24] Tapsell, S.M. and Tunstall, S.M., I wish I'd never heard of Banbury: The relationship between 'place' and the health impacts from flooding. Health \& Place, 14(2), pp. 133-154, 2008.

[25] Lamond, J.E. and D.G. Proverbs. Flood Insurance in the UK - a survey of the experience of floodplain residents. FRIAR (1st international conference on Flood Recovery, Innovation And Response) 2-3 July 2008 One Great George Street, London, UK.: WIT Press, Southampton. 2008.

[26] Siegrist, M. and Gutscher, H., Natural hazards and motivation for mitigation behaviour: people cannot predict the Affect evoked by a severe flood. Risk Analysis, 28(3), pp. 771-778, 2008.

[27] Rotter, J., Generalized expectancies for internal versus external control of reinforcement. Psychological monographs, 33(1), pp. 300-303, 1966.

[28] Coleman, M. and DeLeire, T. An economic model of locus of control and the human capital investment decision. $J$ of Human Resources, 38(3), pp. 701-721, 2003.

[29] McClure, P.J., Walkey, F.H. \& Allen, M., When earthquake damage is seen as preventable: attributions, locus of control and attitudes to risk. 
International Journal of Applied Psychology: an international review, 48(2), pp. 239-256, 1999.

[30] Stajkovic, A.D. and Luthans, F., Social Cognitive Theory and Self Efficacy: Going Beyond Traditional Motivational and Behavioral Approaches. Organizational Dynamics - Field Report, Spring 1998. 1998.

[31] Blennow, K. and Persson, J., Climate change: motivation for taking measures to adapt. Global Environmental Change, 19, pp. 100-104, 2009.

[32] Mileti, D.S. Factors related to flood warning response. US-Italy research workshop on the Hydrometeorology, Impacts, and Management of Extreme Floods; November 1995, Perugia (Italy), 1995.

[33] Sattler, D.N., Kaiser, C.F. \& Hittner, J.B., Disaster Preparedness: Relationships Among Prior Experience, Personal Characteristics, and Distress. Journal of Applied Social Psychology, 30(7), pp. 1396-1420, 2000 . 